\title{
ESCOLHAS, PERCURSOS E TRAJETÓRIAS DE FORMAÇÃO: REFLEXÕES SOBRE A APRENDIZAGEM PROFISSIONAL DA DOCÊNCIA DE PROFESSORES INICIANTES DE GEOGRAFIA
}

\author{
CHOICES, PATHS AND EDUCATIONAL TRAJECTORIES: REFLECTIONS \\ ABOUT BEGINNING GEOGRAPHY TEACHERS PROFESSIONAL LEARNING
}

\author{
Alessandra Bernardes* \\ Júlio Emílio Diniz-Pereira*
}

Resumo: Este artigo tem como objetivo central a compreensão dos processos de aprendizagem da docência por parte de professores iniciantes de geografia da educação básica. Por meio da leitura e análise de questionários aplicados a nove professores, construímos um breve perfil dos respondentes e avançamos na discussão sobre: (1) os processos que conduziram a escolha pela licenciatura em geografia como curso superior e (2) as relações entre formação acadêmico-profissional, iniciação e aprendizagem da docência. Quase totalidade dos professores, mesmo que de maneira crítica, reconhece as contribuições da formação na universidade para sua prática profissional. Entendem a formação como processo contínuo e não restrito aos saberes técnicos. Dessa maneira, valorizam a chamada "teoria" na formação acadêmica, porém afirmam sobre a necessidade de que as disciplinas que tenham esse caráter tomem a realidade escolar como referência para sua organização e desenvolvimento. Nos relatos desses professores, a entrada na escola desencadeou uma série de aprendizagens e reflexões em torno da própria prática e uma avaliação problematizadora da formação na universidade. Conhecer e analisar as trajetórias desses docentes nos trouxe uma série de elementos e indícios fundamentais para uma compreensão mais ampliada e complexificada dos processos de aprendizagem profissional da docência por parte dos professores iniciantes.

Palavras-chave: Aprendizagem da docência. Professores iniciantes. Ensino de geografia.

Abstract: This paper aims at understanding the processes of beginning Geography teachers’ professional learning in Brazil. The analysis of a questionnaire applied to 9 Geography school teachers provided their profile, and discussions about: (1) the processes involved in choosing a teacher undergraduate degree in Geography, and (2) the relationship between pre-service teacher education, first years of teaching, and learning to teach. Most school teachers recognize the contributions of their university teacher education programs to their professional practice. They understand their training as an ongoing process, not restricted to technical knowledge. They value the so-called "theoretical foundation" received through attending their university teacher education programs, but they argue for a greater integration between this theoretical learning and the discussion about the school realities. The contact with the school realities provided learning and reflections about their own practice, and a critical evaluation of the education they received at the university. The knowledge and analysis of these school teachers' trajectories highlighted a number of elements, and essential evidence to a broader and more complex understanding about the processes involved in beginning teachers' professional learning to teach.

Keywords: Professional learning. Beginning teachers. Geography teaching.

\footnotetext{
* Mestranda em educação pela UFMG. E-mail: <alegeoufv@yahoo.com.br>.

* Master student in Education from UFMG. E-mail: <alegeoufv@yahoo.com.br>.

${ }^{* * *}$ Doutor em Educação: Sociologia do Currículo e da Formação de Professores pela Universidade do Estado de Wisconsin, EUA. Professor do Programa de Pós-Graduação em Educação da UFMG. E-mail: <julioemiliodiniz@yahoo.com>.

** Doctor in Education: Curriculum Sociology and Teacher Education from the State University of Wisconsin, EUA. Professor at the Post Graduate Programme in Education at the UFMG. E-mail: <julioemiliodiniz@yahoo.com>.
} 


\section{Introdução}

Importante como espaço formativo dos professores antes mesmo de ingressarem na carreira, a escola amplia seu papel quando se refere ao momento inicial da atuação desses sujeitos como profissionais. Nesse momento e lugar específicos, não apenas como espaço de observação e de algumas intervenções, como no instante da formação acadêmico-profissional ${ }^{1}$, os professores novatos têm a escola como locus privilegiado de aprendizagem da docência.

Como indica a literatura sobre iniciação à docência, a entrada na carreira impõe ao professor um momento intenso em termos de experiências pessoais e profissionais, conduzindo-o a um processo de grande aprendizagem (MARCELO GARCÍA, 1998; TARDIF, 2002; REALI; TANCREDI; MIZUKAMI, 2010). Essa mesma literatura aponta ainda para possíveis elementos que se constituem como importantes para o entendimento dos processos que levam à aprendizagem profissional, em especial no início da carreira.

Situamos os estudos sobre a iniciação à docência no interior do campo da formação de professores, campo este caracterizado por um amplo desenvolvimento nas últimas décadas, tanto em termos quantitativos quanto qualitativos (ANDRÉ, 2011). Entre os temas aos quais se voltam as pesquisas no referido campo está à aprendizagem da docência, tema que aparece com vigor nos últimos anos, obrigando uma reformulação dos estudos sobre formação de professores (MARCELO GARCÍA, 1998).

\footnotetext{
${ }^{1}$ Ao considerar as características da formação de muitos professores brasileiros em exercício, assim como aspectos da própria atividade docente, DinizPereira propõe o uso do termo "formação acadêmica" em detrimento de "formação inicial”. (Ver DINIZPEREIRA, 2008).
}

No presente artigo, baseado em resultados de uma investigação, buscamos compreender os processos de aprendizagem da docência por parte de um grupo de nove professores e professoras de gGeografia, atuantes na educação básica na região metropolitana de Belo Horizonte. Por intermédio da leitura e análise de questionários, algumas reflexões/afirmações trazidas (ou ocultadas) pelos respondentes nos parecem importantes na construção dos caminhos para a compreensão de sua aprendizagem da docência.

Após realizar um breve perfil dos respondentes, avançamos na discussão sobre (1) os processos que conduziram à escolha pela licenciatura em geografia como curso superior e (2) as relações entre a formação acadêmico-profissional, a iniciação e a aprendizagem da docência. De que maneira a docência e o ensino da geografia, de maneira mais pontual, se apresentam nos caminhos percorridos por esses professores? Que avaliação esses sujeitos fazem acerca dos cursos de graduação pelo quais passaram? Quais os possíveis desdobramentos desse momento da formação para suas primeiras experiências na escola como professores? Quais as relações entre as escolhas e trajetórias desses professores e seus processos de aprendizagem profissional da docência?

A partir da identificação e compreensão desses elementos, acreditamos ser possível a construção de uma compreensão mais ampliada e complexificada da aprendizagem da docência a partir dos percursos e processos vivenciados por professores em início de carreira. 


\section{Breves apontamentos sobre iniciação e aprendizagem da docência de jovens professores}

Buscando compreender de forma mais sistemática como se processa a aprendizagem da docência no início da carreira, partiremos de dois debates: o primeiro deles se refere à temática da iniciação à docência e o segundo, à aprendizagem da docência, com foco na etapa inicial da carreira. Para ambos os temas, ainda que apresentando uma série de lacunas, há um conjunto interessante de trabalhos que nos permite conhecer e caracterizar de maneira mais geral a entrada na carreira e nos servir, em alguma medida, como base teórica e empírica para a realização das reflexões acerca da aprendizagem da docência por professores iniciantes de geografia, como proposto.

Embora sistematicamente esquecida pelas instituições universitárias e demais instituições voltadas para a formação docente, a iniciação à docência se constitui como fundamental no processo de desenvolvimento profissional dos professores (MARCELO GARCIA, 1999; ABARCA, 1999; MARIANO, 2005). Englobando os primeiros anos de atuação no magistério², a iniciação à docência é um importante momento da formação do professor, no qual ele se insere no meio onde desenvolverá suas atividades, passando a se constituir e ser (auto) reconhecido como profissional.

\footnotetext{
${ }^{2}$ Não há consenso no que se refere à delimitação temporal do período de iniciação à docência. Em uma revisão da produção acadêmica sobre a temática, Lima et al (2007) apontam para diferentes marcações para aquilo que se denominaria como iniciação à docência. Ressaltam, no entanto, que a principal referência para essa definição é a obra de Huberman (1992), onde o autor descreve o ciclo de vida dos professores, definindo a iniciação como período que se estende da entrada na carreira até os três primeiros anos de exercício do magistério.
}

É quando o professor estabelece e fortalece as bases sobre as quais dará continuidade (ou não) à sua prática docente e seu processo de formação, tendo forte influência sobre todo o percurso posterior da carreira. Os primeiros anos de profissão são decisivos na estruturação da prática profissional, podendo ocasionar o estabelecimento de rotinas e certezas cristalizadas sobre a atividade de ensino que acompanharão o professor ao longo de sua carreira (NONO, 2011) e ter reflexos diretos nos seus processos de aprendizagem profissional e profundos desdobramentos, muitas vezes negativos, sobre o ensino (NONO, 2005; REALI, TANCREDI; MIZUKAMI, 2010).

Uma importante característica da iniciação, sistematicamente apontada e, por vezes analisada na literatura sobre a iniciação à docência, é o denominado "choque de realidade". Trata-se de um dos desdobramentos relativos ao momento de transição da condição de estudante para a de professor, resultado de um encontro, muitas vezes tenso, entre as idealizações construídas ao longo da formação acadêmico-profissional do professor e a realidade escolar (VEENMAN, 1988 apud MARIANO, 2005). Misturando aspectos associados à "sobrevivência" e à "descoberta”, como destaca Huberman (1992), a iniciação à docência é assim caracterizada por intensos conflitos, incertezas, mas também por momentos de satisfação, descobertas e grande desejo dos iniciantes de aprenderem a profissão e se tornarem, cada vez mais, melhores professores, apesar das adversidades vivenciadas nessa etapa da carreira (NONO, 2005; MARCELO GARCÍA, 1998; DINIZ, 1998).

Quase sempre desamparados pela escola, esses professores têm que dar conta do seu próprio processo de aprendizagem profissional, que possui, nessa etapa da carreira, grandes especificidades. Dentro de uma

Olhar de professor, Ponta Grossa, 15(2): 251-267, 2012. Disponível em <http://www.uepg.br/olhardeprofessor> 
cultura escolar, onde permanece a conveniente crença de que a passagem pela universidade garante a plena formação para o exercício do magistério, a escola quase sempre se exime da responsabilidade de acompanhar e dar apoio aos professores iniciantes, orientando a inserção e a socialização dos professores em seus contextos de trabalho (REYES, 2011).

Dentro de um modelo de inserção profissional, com o sugestivo nome, "nadar o hundirse" (nadar ou afundar-se) (VONK, 1996 apud BRITO et al., 2005) ${ }^{3}$, ao professor iniciante é atribuída toda a responsabilidade por se inserir profissionalmente na docência logo que termina sua formação dita inicial. Comumente nesse tipo de inserção, os professores novatos são submetidos aos "ritos de iniciação" (BRITO et al., 2005), onde são expostos a "provas" para mostrar que são capazes de ensinar e realizar as tarefas mais difíceis e complexas, aquelas que ninguém deseja assumir na escola ${ }^{4}$.

\footnotetext{
${ }^{3}$ Baseados em Vonk (1996), Brito et al aponta para a existência de quatro modelos de inserção profissional, quais sejam: "nadar o hundirse" (nadar ou afundar), "colegial", "competencia madatada" e "modelo mentor protegido formalizado". Esses modelos se estruturam a partir de três componentes, o "pessoal", o "técnico" e o "institucional”, e se definem, de maneira simplificada, às formas de acompanhamento (ou sua ausência) do jovem professor quando do seu ingresso na escola. No primeiro modelo, não há qualquer participação formal de terceiros na inserção do professor, que deve provar suas competências por meio de seus resultados e interações na escola. No segundo modelo, ainda que não formalmente estabelecido, há um acompanhamento do professor quando inicia sua carreira. O terceiro se caracteriza pelo estabelecimento de uma relação formal, hierárquica entre um professor denominado "guia" e o professor iniciante, na qual o primeiro transfere uma bagagem de competências básicas ao segundo. O último modelo se define pela existência de um programa sistemático de indução profissional do iniciante, que demanda uma preparação e treinamento daqueles que irão acompanhar o novato em suas atividades na escola.

${ }^{4}$ Freitas (2002) apresenta um estudo bastante minucioso acerca desses ritos e provas. Ao analisar a inser-
}

O aspecto da aprendizagem da docência é de corrente presença na literatura sobre professores iniciantes. Tardif (2002) refere-se à iniciação como um momento de uma "aprendizagem rápida", na qual o professor acumula sua experiência fundamental e cujos aprendizados têm valor de confirmação. Marcelo García (1998) refere-se ao primeiro ano da docência como "período de aprendizagem intensa”, baseada no esquema ensaio-e-erro e com predomínio do valor prático. Reali, Tancredi e Mizukami (2010) referem-se à iniciação à docência como "período crítico do desenvolvimento profissional”, devendo ser dada a devida atenção às diferentes necessidades formativas dependendo da fase da carreira na qual se encontram. Reyes (2011) afirma que no início da carreira dos professores são adquiridos, em um curto período de tempo, os conhecimentos e competências profissionais necessários à profissão, algo ocorrido frequentemente de forma solitária.

Associadas a características (consideradas) intrínsecas ao ingresso na carreira, nas condições dentro das quais comumente se realiza esse processo, a aprendizagem que caracteriza o início do magistério é marcada, muitas vezes, por grandes dificuldades e uma multiplicidade de intensos sentimentos. É o estar na escola, na condição de

ção de professores em escolas da zona rural e da zona urbana de dois municípios de Minas Gerais, mostra como as professoras das séries iniciais que ingressavam na carreira eram levadas a assumir as turmas tidas como as "mais difíceis" das escolas - turmas com um desnível maior em termos de conteúdos aprendidos e ritmos de desenvolvimento; turmas com maior heterogeneidade sociocultural; turmas mais indisciplinadas etc. Também as jovens professoras foram direcionadas a assumir cargos na zona rural, cujas escolas se caracterizavam pela falta de material didático, pouca possibilidade para troca de experiências e acompanhamento pedagógico, existência de turmas multisseriadas e dificuldade de conciliação entre a vida profissional e a pessoal. 
professor, que leva o iniciante a descobrir os limites dos seus saberes para atuarem com professores e os conduz a buscar, dentro de um contexto marcado pela necessidade, (re) construir os saberes necessários à sua atividade profissional. Como afirmam Tardif e Raymond (2000), o início da atividade no magistério se constitui uma fase crítica em relação às experiências anteriores e aos reajustes a serem realizados em função da realidade do trabalho e do confronto inicial com a dura e complexa realidade do exercício da profissão.

Concomitantemente ensinando e aprendendo a ensinar (MARCELOGARCÍA, 2009), a escola, com seus sujeitos e relações, normas explícitas ou tácitas, instruções sobre formas de estar/se comportar (inclusive em espaços extra-escolares), é para o jovem professor, lócus privilegiado da formação no início da carreira. Como aponta Tardif (2002), a experiência de trabalho parece ser a fonte privilegiada do saber-ensinar, em que seinserem também determinados fatores cognitivos e os conhecimentos sociais partilhados com os alunos e demais professores. Ao dar início à sua prática profissional, diante da imprevisibilidade e complexidade características da sala de aula, o professor passa por um período de intenso confronto entre aquilo que foi ensinado e aprendido ao longo de sua formação (NONO, 2011).

Ainda de acordo com Nono (2011), a iniciação à docência é um período no qual os professores procuram ajustar suas expectativas e ideias sobre a profissão às condições reais de trabalho que encontram. Com vistas a permanecer na profissão e manter certo equilíbrio diante dos sentimentos contraditórios que marcam a entrada na carreira, os professores buscam lidar com uma série de limitações que atuam diretamente sobre suas representações acerca da escola, da docência, dos alunos. Assim, é também nesse momento que se dá parte fundamental da construção de sua (auto) imagem como docente. Tal construção se processa associando tanto aspectos da trajetória e subjetividade de cada professor, quanto seu percurso formativo acadêmico e as condições nas quais se inserem e se desenvolvem em sua atividade profissional.

Partindo dessas formulações, caminhamos no sentido de conhecer e analisar o que dizem os iniciantes respondentes da pesquisa que vem sendo desenvolvida sobre suas experiências, encontros e desencontros com suas escolhas e expectativas sobre a docência e a docência em geografia, de maneira particular, construídas nessa etapa da profissão. Tomando as discussões realizadas como referência e base para reflexão/problematização, acreditamos ser possível construir elementos que nos auxiliarão no entendimento mais sistemático acerca da aprendizagem da docência para professores em fase inicial da carreira.

\section{Entre escolhas, percursos e (des) encontros: iniciar a docência em geografia}

Como parte da coleta de dados desta pesquisa, foram aplicados questionários a nove professores ${ }^{5}$, todos com o título de licenciatura plena em geografia, atuantes (ou com passagem como docentes) na escola básica e egressos de instituições de ensino superior situadas em Belo Horizonte ${ }^{6}$. O grupo

\footnotetext{
${ }^{5} \mathrm{O}$ grupo de professores foi contatado, sobretudo, por meio de endereço eletrônico, sendo este também o meio pelo qual lhes foi enviado o questionário a que responderam.

${ }^{6}$ Após sucessivas tentativas de localizar professores com o perfil desejado para a pesquisa por meio de secretarias e superintendências de educação e universidade/faculdades formadoras, o caminho mais profícuo foi a divulgação em grupos na internet, vinculados à
} 
é composto por quatro mulheres e cinco homens, cujo ano de nascimento varia de 1974 a 1989, tendo assim os professores idades aproximadas entre 23 e 38 anos, com certa prevalência de professores com idade igual ou próxima de 30 anos (dos nove professores, quatro nasceram em 1982).

No que se refere ao tempo de início de atuação no magistério (para dois deles iniciado antes da obtenção do título de licenciados), esses professores o fizeram entre os anos de 2006 e 2012. Apresentam, assim, entre cerca de seis e menos de um ano de início da atuação profissional na docência. Entre os professores, cinco deles tiveram sua primeira experiência como professores na educação básica, entre menos de um e três anos e os quatro demais, entre quatro e seis anos.

Quanto à trajetória escolar, para o conjunto de professores respondentes, excetuando-se dois deles, todos cursaram a educação básica em escolas públicas, o que, para o caso brasileiro, marcado por fortes desigualdades no que se refere à "qualidade" do ensino nas diferentes redes, pode apontar para uma possível composição em termos de nível socioeconômico do grupo de pesquisa$\operatorname{dos}^{7}$.

Geografia e, sobretudo, indicação direta de pessoas. Seguindo essa trilha, muito daquilo que se almejava inicialmente, especialmente no que se refere ao tempo de atividade na docência e a rede a qual se vinculariam os professores, foi alterado. Esse fato, no entanto, fez enriquecer a amostra que, no momento, se compõe de um grupo com trajetórias e experiências bem distintas no que se refere à sua escolarização, formação acadêmica, processo de entrada na carreira e trajetórias profissionais. As universidades das quais esses professores são egressos são, a saber: Universidade Federal de Minas Gerais - UFMG, o Centro Universitário de Belo Horizonte - UNIBH e a Pontifícia Universidade Católica de Minas Gerais - PUC-MG.

${ }^{7}$ Outras informações podem se somar a esse dado. Uma das respondentes afirma dar aulas desde os sete anos, ajudando a mãe lavadeira com as despesas da família. Outro elemento está associado ao pertencimento
Quanto ao ensino superior, em nível de graduação, quatro estudaram em instituição federal e os demais o fizeram em instituições privadas. Desse conjunto, somente dois professores não cursaram ou estão vinculados no momento a cursos de pós-graduação, a maior parte em instituições particulares. Prevalecem as pós-graduações stricto sensu, sendo o geoprocessamento o mais cursado. Há ainda um professor cursando pós-graduação, também stricto sensu, cuja temática é a Educação à Distância, um mestrando e uma mestra em educação.

Situados em contextos onde cada vez mais se ampliam as exigências em termos de domínio de informações e capacidade de difundi-las através de diferentes ferramentas, com destaque para as tecnologias da ciência e da informação, os professores, movidos também por desejos particulares, buscam, cada vez mais, se "capacitar/instrumentalizar”. Inseridos em uma lógica na qual o conhecimento deve ser apreendido de maneira rápida para posterior (fácil) aplicação, buscam aprender novas técnicas que lhes sejam úteis. Nessa modalidade de pós-graduação, bastante mercantilizada, há pouco ou nenhum espaço para uma reflexão mais sistemática acerca da realidade na qual se

étnico-racial. Entre os respondentes, três deles se declaram negros e uma se define como morena/parda/ negra. Considerando as desigualdades históricas entre sujeitos de diferentes pertencimentos étnico-raciais no Brasil, mais pontualmente entre brancos e negros, com uma forte carga negativa para os segundos, é possível pensar que pode se tratar de um grupo composto por sujeitos que não se encontram entre aqueles com maior nível socioeconômico. Não entendemos o pertencimento etino-racial como um determinante, porém dentro da estrutura histórico-social brasileira, trata-se de algo que não podemos ignorar. No entanto, dentro de um quadro de grande multiplicidade, ressaltamos que esse dado deve ser tomado com muita cautela. No caso desta pesquisa, trata-se de indícios, já que não foi colocada nenhuma questão objetiva sobre a condição socioeconômica dos sujeitos. 
inserem os profissionais da docência. Ademais, os cursos escolhidos pela maior parte dos respondentes não têm uma vinculação direta com a atividade docente, tal como a realizam, nem com a etapa do desenvolvimento profissional na qual se encontram.

Esse fato talvez possa nos informar acerca de certos aspectos em torno da docência na atualidade, tanto simbólica, quanto materialmente. Sobre o primeiro ponto, por exemplo, a escolha dos professores pode apontar para a existência de um pensamento corrente em torno da formação docente, no qual a aprendizagem profissional se basta com o exercício da profissão. No que se refere ao aspecto material (mas também simbólico), podemos apontar a desvalorização da docência, sendo esses cursos, por exemplo, tomados pelos jovens professores como possibilidade de ampliar seu escopo de atuação profissional, talvez até mesmo visando abandonar a docência, algo não raro no início da carreira.

Perguntados sobre atividades de formação institucionais voltadas ao trabalho docente, realizadas ao longo dos seus primeiros meses/anos como professores, confirmam o que a literatura já vem mostrando e problematizando: quando da presença de alguma ação institucional de formação, o que se observa são ações pontuais, com base em palestras e cursos de curta (curtíssima) duração, desencontrada com a etapa do desenvolvimento profissional no qual se encontram os professores e, no caso dos iniciantes da geografia, desvinculados de seu campo disciplinar. Sobre esse último ponto, a professora Leila relata, com descontentamento, ter participado de uma formação voltada à matemática. A professora Aline destaca que, nas ações de formação empreendidas nas escolas de uma das redes na qual atua, "a geografia é sempre deixada de lado”. Segundo ela, português, matemática e ciências, disciplinas que compõem o quadro daquelas nas quais se pautam as avaliações de desempenho, recebem toda a prioridade nas ações sistematizadas de formação.

Descompassos entre as ações formativas ofertadas pela escola/rede de ensino e as necessidades dos professores também foram observados nos relatos dos professores. As demandas formativas desses professores, que passam tanto por necessárias reflexões e, para eles, urgentes formas de ação, não são plenamente atendidas. À questão da indisciplina, forte presença nos relatos de alguns dos iniciantes, não é dada a devida atenção. O professor Guilherme ressalta que houve uma palestra sobre indisciplina e que, por um momento, responderam a uma dificuldade que tinha. Entretanto, avalia que a falta de acompanhamento por parte da escola fez com que os desafios continuassem, tendo a atividade de formação pouca efetividade. Já a professora Aline afirma seu desejo por melhorar suas aulas através da ampliação do repertório de conhecimentos em torno de técnicas de ensino dos conteúdos que leciona.

Dentro de um contexto de grande aumento do escopo de atividades pelas quais o docente deve se responsabilizar e por elas responder socialmente (GARCIA; ANADON, 2009; FANFANI, 2007), a professora Mariana chama atenção para a necessidade daquilo que denomina "estrutura pedagógica”. Somada à existência de uma estrutura física adequada, aponta para a importância de a escola tomar para si atividades que vêm sendo delegadas aos professores, associadas tanto a aspectos mais gerais do funcionamento da escola, quanto a ações mais pontuais relacionadas à atividade do ensino.

Questões que são problemáticas para o conjunto dos professores tornam-se, para os iniciantes, ainda mais. Como colocado 
anteriormente, a iniciação à docência é um momento de tatear constante, um momento no qual o professor deve ensinar e aprender a ensinar, ao mesmo tempo. Dentro das condições nas quais se realizam os processos formativos ao longo da vida dos professores, a entrada na carreira exige enormes esforços.

Não lhes são garantidos o tempo e as condições necessárias para seu aprimoramento profissional, e sua já referida rápida aprendizagem se dá, quase sempre, a duras penas $^{8}$. Termos que são utilizados na literatura para caracterizar a iniciação à docência, como o "choque de realidade" e a "sobrevivência”, se tornam plenos em sentido para experiência desses professores.

Voltemo-nos agora para algumas reflexões em torno da formação acadêmica dos iniciantes e de suas relações com a atividade docente desses professores. Diferentes foram as motivações para que os professores iniciantes participantes desta pesquisa escolhessem a geografia como curso superior, sobretudo a modalidade bacharelado, escolha inicial de seis entre os nove respondentes. No que tange às motivações apresentadas, dois professores explicam que a escolha se deu por influência dos pais ou colegas, não havendo muita clareza sobre essa opção. Como um deles afirma, "não foi uma escolha bem planejada".

Para outros, foi uma escolha que se deu quase que por meio de um "estudo" sobre as possibilidades dentro do campo, tanto aqueles que já almejavam se tornar professores quanto para os demais. Para esse segundo grupo, a opção pelo curso se deu de manei-

\footnotetext{
${ }^{8}$ Reyes (2011) realiza uma ampla pesquisa na qual apresenta experiências de recepção dos professores em início da carreira. Segundo o autor, em muitos países, os professores iniciantes têm sua carga de trabalho na escola reduzida e são acompanhados por professores com mais tempo de atividade na escola. Há também experiências de professores que recebem formação específica para o campo disciplinar no qual atuam.
}

ra gradual e orientada por um interesse por temáticas específicas da geografia, como o meio ambiente ou temas da denominada Geografia Humana. Duas professoras afirmam terem feito vestibular para Ciências Sociais antes de Geografia.

Esse quadro parece reproduzir "dilemas internos” vivenciados pela própria ciência geográfica: de maneira concomitante, um campo historicamente fragmentado entre duas grandes áreas - a Geografia Física e a Geografia Humana - e uma "ciência de síntese" que tudo explica e onde tudo cabe. Além de gerador de certas imagens da geografia enquanto área do saber, é possível que essas características do campo gerem também representações sobre a geografia na escola, algo a ser protagonizado pelo professor dessa disciplina. Quais são as atribuições do professor de geografia na escola? O que cabe a ele enquanto atividades a serem desenvolvidas? O que é esperado desse professor e o que ele espera de si enquanto docente dessa disciplina? Essas são questões que têm vinculações diretas com a construção da identidade do professor dessa disciplina e, dessa forma, é possível que tenham desdobramentos sobre os processos de aprendizagem da docência, neste caso, dos jovens professores.

Outra referência importante para os professores que responderam ao questionário no que se refere à sua escolha pela geografia foi a convivência com, o que denominaram, um bom professor da disciplina ao longo da sua escolarização e/ou um apreço pelos temas abordados. Os professores afirmam que gostaram da disciplina na escola/no Ensino Médio ou que tiveram um professor muito bom, "simplesmente FANTÁSTICO”, como coloca uma das professoras (destaque da professora).

Diferentemente de alguns campos do saber, mesmo aqueles que têm historicamente lugar entre as disciplinas escolares, a 
geografia tem a escola como principal meio de contato e conhecimento acerca do seu conteúdo e, de maneira não tão objetiva, das possibilidades em termos de atuação profissional, inclusive a docência. Esse fato, mesmo associado a experiências positivas na escola com a disciplina e/ou com seus professores, parece não ter sido decisivo na escolha pelo curso. Como visto, a maior parte dos professores não almejava a docência como futura atividade profissional ao ingressar no ensino superior. Como afirmam:

"minha intenção era fazer bacharelado" (professora Leila),

a "licenciatura nunca fez parte dos meus planos” (professor Guilherme),

"a princípio [a escolha pela geografia] foi totalmente voltado para o bacharelado" (professor Tales),

“não pensava em dar aula, pensava em trabalhar junto aos atingidos por barragens” (professora Mariana).

A licenciatura, que para a quase totalidade desses professores era uma segunda opção, foi se tornando uma possibilidade ao longo do curso e mesmo após seu término. Dois professores, Leila e Fernando, mesmo que desejosos por se formarem somente como bacharéis ou com as duas habilitações, concluíram sua graduação somente na licenciatura. A professora Mariana relata que teve uma relação muito boa com a faculdade de educação onde cursou muitas disciplinas voltadas ao magistério, e que isso a conduziu para a docência, atualmente sua principal, mas não única atividade profissional. Professor Guilherme, por sua vez, afirma que quando formado se viu "excluído do mercado técnico" e recebeu uma oportunidade de lecionar na escola onde estudou, aceitando a proposta.

Há, no entanto, entre esses professores, alguns que tinham clareza sobre a esco- lha pela docência. Os sujeitos que compõem o grupo, duas professoras e um professor, afirmam que a licenciatura sempre fez parte dos seus planos. Mesmo com esse ponto em comum, em seus relatos, é possível perceber diferenças em suas trajetórias de escolha pela licenciatura em geografia. A primeira delas é que, diferentemente do grupo anterior, para esses professores a geografia na escola ou no cursinho pré-vestibular, os bons professores e o apreço pela matéria aparecem como elementos que tiveram importante influência na escolha.

Outro aspecto a destacar é o fato de que dois desses professores apontam a docência em si como busca no curso superior. Sem ainda clareza daquilo que gostariam de ensinar quando docentes, a ideia era ser professor/a. Certo dessa opção, para o professor Pedro, a questão era decidir o que cursar no ensino superior para atuar na profissão, se geografia ou história, algo que foi definido com base em conversas com docentes dessas duas disciplinas. Já a professora Aline relata que o magistério se colocava, dentro da sua trajetória até o momento da escolha pela geografia, como curso superior, como uma boa atividade profissional por parecer lhe permitir maior controle do tempo do trabalho e garantir autonomia profissional ${ }^{9}$. Para esse conjunto de jovens docentes, "a licenciatura os levou à geografia", como bem sintetiza a professora Clara.

\footnotetext{
${ }^{9}$ Antes de ser professora, estudou turismo e lazer no CEFET-MG e atuava como atendente em um serviço telefônico que informava sobre turismo e cultura em Minas Gerais e no Espírito Santo. Insatisfeita com o perfil do curso e com o trabalho que realizava (trabalhava em feriados, finais de semana e férias), afirma que, mesmo sem saber de forma clara e consistente como hoje, se decidiu por um novo curso pensando em algo que a tirasse do lugar onde estava. Lecionando desde cedo para ajudar a mãe com as despesas, isso somado a outras experiências em torno da geografia no pré-vestibular, optou por esse curso.
} 
Os processos de escolha pela geografia e suas distintas habilitações, bacharelado e licenciatura, parece ter reverberações mais ou menos diretas no momento da formação acadêmica desses sujeitos com desdobramentos para sua aprendizagem da docência nessa etapa da formação e no momento da entrada na carreira. Alguns professores relataram que seu envolvimento com as disciplinas voltadas à licenciatura foi aquém daquilo que poderia ter sido, fato que associam à escolha pelo bacharelado. Apesar disso, mesmo que com forte teor crítico, a grande maioria dos professores avaliou positivamente sua formação para a docência na universidade.

Segundo esses jovens docentes, a presença de formadores na graduação com experiência na educação básica parece ser fundamental para uma boa formação para a docência. Ter atuado ou atuar como professor nesse nível de ensino, com passagem por diferentes experiências e atuação na rede pública, são bem vistos pelos professores iniciantes. Para os respondentes, essa experiência permite ou mesmo garante ao formador organizar, conduzir e avaliar a formação para o magistério com maior proximidade daquilo que seja, efetivamente, a escola. Trata-se de algo que lhe dá credibilidade, que gera maior envolvimento dos futuros professores com as aulas e, sobretudo, conduz a um importante rompimento com as fronteiras entre a denominada teoria e a prática na formação acadêmica.

Essa é uma fala recorrente entre os professores que responderam ao questionário. Para esses jovens docentes, a formação na universidade está distante da realidade da escola e, em grande medida, isso ocorre porque os professores formadores assim também estão. Afirmam que os formadores conhecem pouco e de maneira indireta a escola básica, portanto, de maneira muito pou- co ou nada condizente com o movimento da realidade nesses espaços. Oferecem em seus cursos visões que quase sempre não correspondem ao que se passa na escola, abordando-a de forma ampla e genérica, tocando de maneira distante em aspectos que constituem o cotidiano da/na escola. Assim, formam futuros professores para uma escola e alunos ideais, algo que como ressaltam os professores Fernando e Aline, nunca existiu e nunca existirá.

Em seus relatos, os professores iniciantes apontam para a necessidade de que cursos de formação acadêmica para licenciatura se voltem à escola, aos seus sujeitos e/ em suas relações, aos seus dilemas, aos seus problemas, às suas estruturas e à prática docente, pautando-se em espaços e pessoas concretas, social e espacialmente localizados. Falam sobre a importância de garantir aos futuros professores certos saberes e, de maneira mais pontual, um saber-fazer condizente com aquilo que encontrarão em sala de aula como professores. Dois professores afirmam que, ao longo da sua passagem pela universidade, outras atividades, que não as aulas, foram extremamente importantes e decisivas para a construção/manutenção da motivação para (seguir com) seu envolvimento com a licenciatura e de construção de saberes que deram um verdadeiro suporte quando do início das suas atividades como professores. Atividades de extensão e projetos de pesquisa relacionados à docência cumpriram um importante papel no processo de aprendizagem da docência desses professores.

Além de expressarem de maneira objetiva em suas falas, a discussão sobre uma formação docente desvinculada da realidade da escola aparece diluída nas respostas dos jovens professores, também fortemente através de suas reflexões em torno dos conteúdos, da estrutura, da organização e o desenvolvimento dos cursos de nível 
superior pelos quais passaram. Ao chamar atenção para a necessidade de uma efetiva aproximação entre a formação docente e a escola, alguns desses professores valorizam fortemente os momentos de estágio e das práticas de ensino, disciplinas mais “práticas”, segundo eles.

Essas disciplinas, mais do que as "teóricas", "muito chatas e distantes da realidade”, segundo a professora Leila, são vistas como momentos importantes da formação docente. O estágio, por exemplo, é tomado como um momento em que, segundo os docentes, seria realizada uma verdadeira aproximação com a escola, oferecendo possibilidade de contato e conhecimento do que, de fato, se passa aí. Somadas às discussões sobre a experiência do estágio na escola, a professora Aline afirma que esse momento garantiu um contato mais próximo com o trabalho que viria a desenvolver, suas angústias, suas tristezas, seus limites, suas possibilidades.

Também presente na literatura sobre a iniciação à docência, o aspecto da desvinculação entre formação acadêmica e atividade docente ou uma vinculação não tão efetiva entre elas, no que se refere ao atendimento das necessidades dos jovens professores, aparece com força nos relatos dos respondentes. Há, no entanto, dois elementos que nos parece importante ressaltar nos relatos desses professores: (1) as reflexões em torno das ditas "disciplinas teóricas” na formação docente e (2) as concepções acerca da formação do professor, neste caso, do professor de geografia para atuar na educação básica.

No que se refere ao primeiro ponto, mesmo demonstrando grande apreço pelas disciplinas "práticas", as “teóricas" aparecem com destaque na fala dos professores, sobretudo os egressos de uma das instituições ${ }^{10}$. Diferentemente de uma negação em torno das disciplinas de cunho teórico na formação, parece não haver uma crítica pontual e objetiva aos conteúdos dessas disciplinas em si, mas na sua (des)vinculação com a atividade profissional a ser desenvolvida pelo futuro professor. Não há um discurso em torno da necessidade do abandono de disciplinas "teóricas", ou da negação da pesquisa como parte da formação acadêmica; há, sim, uma reflexão acerca da abordagem desses conjuntos disciplinares para a futura atividade do professor.

Para os professores iniciantes participantes dessa pesquisa, estas disciplinas permitiram a apreensão/construção de conhecimentos e habilidades importantes sobre a escola e sobre os alunos. Apesar de não terem atingido de maneira plena o esperado por eles, o que parece ter sido percebido, sobretudo, quando iniciaram a docência, disciplinas como psicologia, sociologia e política da educação, tiveram sua importância reconhecida por parte dos professores. Destacamos que os professores que compõem esse grupo se mostraram bastante reflexivos e expressaram, alguns com mais clareza do que outros, os limites e as contribuições dessas disciplinas para sua prática profissional. A professora Aline associa, com grande minúcia, o que estudou no ensino superior e aquilo que sua prática em sala de aula demanda, apontando as lacunas existentes. Já a professora Mariana reconhece que, mesmo sem se lembrar daquilo que foi estudado, ao lecionar, percebe que essas disciplinas foram importantes para sua formação.

Avancemos na discussão do segundo ponto destacado, as concepções acerca da formação do professor para a educação básica.

\footnotetext{
${ }^{10}$ A instituição a que nos referimos é a Universidade Federal de Minas Gerais - UFMG.
} 
Quando perguntados sobre as contribuições da formação acadêmica para a prática docente na escola, exceto um dos professores, todos afirmam (de maneira quase sempre crítica) que a passagem pela universidade contribuiu para sua atividade profissional. Também afirmam, no entanto, que a docência somente foi efetivamente aprendida a partir do exercício do magistério. Esses relatos guardam em si grande riqueza e nos trazem indícios de que parece haver um movimento importante no que se refere às concepções sobre a aprendizagem da docência por parte das novas gerações de professores, ao mesmo tempo em que apontam para algumas continuidades.

Apesar de grandes esforços em torno da construção de concepções mais ampliadas acerca da docência, entendê-la como algo nato, intrínseco ao indivíduo é uma ideia que se encontra ainda bastante difundida socialmente. Para ser professor, bastaria ao sujeito "ter jeito para a coisa", "nascer para isso", conhecer o conteúdo, ter talento, ter bom senso, cultura, experiência ou seguir a intuição. A docência seria assim, como problematiza Gauthier (1998), um ofício sem saberes, desprovido de um repertório de conhecimentos próprio do profissional do magistério. Sendo o sujeito portador das capacidades e habilidades necessárias ao exercício da docência, a formação de professores não teria função alguma, senão aquela de potencializá-las.

Essa concepção de docência e de formação não é compartilhada pelos professores respondentes, não havendo referências em seus relatos sobre a existência de uma qualidade inata ou vocação como aspecto do seu desenvolvimento profissional. Talvez, por reflexões realizadas dentro da universidade ao longo dos cursos de graduação ou através da própria experiência como professores iniciantes, esses docentes parecem se aproximar mais do entendimento da for- mação como processo, como algo que se desenvolve ao longo da vida e da atividade profissional na docência. A afirmação de que "a aprendizagem da docência é um tipo de aprendizagem”, a princípio óbvia, como ressalta Sanmamed (1995), parece fazer grande sentido para os respondentes.

Partir da ideia de que a formação docente é um continuum, conduz ao entendimento de que há um processo constante de aprendizagem por parte do professor acerca de diferentes aspectos relativos à sua profissão. Com muita clareza, e por vezes indignação ${ }^{11}$, os professores reconhecem que sua formação não se encerrou com a sua diplomação, sendo o ingresso na escola momento fundamental para sua aprendizagem da docência. Mesmo percebendo as contribuições da formação acadêmica, alguns dos professores afirmam que foi na escola aprenderam a "prática".

Há aqui, um destaque a ser feito. Para parte dos professores, a formação como um continuum, no que tange às relações entre formação acadêmica e iniciação à docência, neste caso, parece ser entendida como um processo no qual há uma acumulação linear e fragmentado de saberes. Na universidade, se aprende a "teoria" e na escola, se aprende a "prática”, o "como lecionar", havendo funções marcadamente específicas no interior de cada uma dessas "etapas” da formação.

\footnotetext{
${ }^{11}$ Essa clareza, em alguns casos, foi construída a partir de momentos de grande dificuldade vivenciados pelos iniciantes. Percebem, tal como já apontado por Reyes (2011), que a posse do diploma e a finalização da graduação não lhes garantem condições plenas para o exercício do magistério. Em consonância com Nono (2011), também para parte dos respondentes desta pesquisa, a iniciação à docência é um período no qual os professores buscam ajustar suas expectativas e ideias sobre a profissão às condições reais de trabalho que encontram, procurando lidar com uma série de limitações que atuam diretamente sobre suas representações em torno da docência.
} 
Como aponta o professor Tales, "nesses dois anos de licenciatura, aprendi a ser professor na prática, dentro de sala de aula, com turma de 33 alunos”. Ao avaliar os estágios, a professora Mariana afirma que eles a colocaram em contato com a sala de aula e a ensinaram a observar desde o espaço físico da escola até a relação entre os professores e alunos, mas não a ensinaram a dar aula.

Não de maneira passiva e acrítica, esses professores, ao mesmo tempo em que afirmam sobre uma cisão clara existente entre essas duas etapas da formação, apontam para os limites da formação acadêmica e se questionam sobre ela. A professora Aline faz a seguinte reflexão: "Tem horas que eu penso: Puxa vida! Se aquele/aquela professor/a tivesse me ensinado sobre isso, eu estaria sofrendo menos hoje!”. Reformulando esse questionamento, poderíamos assim nos indagar: Outro modelo de formação na universidade seria capaz de minimizar os aspectos negativos do anteriormente referido "choque de realidade"? Como colocado anteriormente, naturalizar o choque de realidade nos parece bastante delicado e algo que pode legitimar a manutenção de dadas concepção e ações de formação na universidade: uma formação baseada em uma escola e em um aluno ideais, cujos conteúdos das disciplinas "teóricas" se encontram desvinculados das necessidades efetivas do trabalho a ser desenvolvido pelo futuro professor, como apontam os respondentes.

Os jovens professores reclamam um olhar mais cuidadoso para o aspecto da docência em sua formação universitária, tanto no que refere a aspectos da relação com os alunos, quanto no que se refere ao trato dos conteúdos. A "serventia" daquilo com que tiveram contato ao longo da graduação para a atividade docente aparece constantemente nos relatos. São comuns afirmações como "parte do curso serviu, outra não”; “algumas disciplinas serviram, outras não"; "tal abordagem desse conteúdo serviu, outra não serviu". A "utilidade" dos conteúdos parece importante para os jovens professores, algo que percebem com o exercício da profissão na escola ${ }^{12}$.

Como apontam Tardif e Raymond (2000), o ingresso no magistério se constitui uma fase crítica em relação às experiências anteriores e aos reajustes a serem realizados em função da realidade do trabalho e do confronto inicial com a dura e complexa realidade do exercício da profissão. A escola, como instância importante na formação inicial, torna-se, para o novato, espaço privilegiado para isso e, no que se refere à aprendizagem da docência em si, a escola ocupa uma centralidade ainda maior.

Segundo aponta Tardif (2002), ao iniciarem sua atividade na escola, os professores percebem que os saberes escolares são mais pragmáticos e divergem em muito daqueles vinculados pela universidade. Nesse momento se dão conta dos limites dos seus saberes pedagógicos e valorizam aquilo que podem "transferir/aplicar" para/na sala de aula. No caso dos professores participantes desta pesquisa, a iniciação à docência fez emergir uma série de demandas relacionadas ao trabalho do professor, algumas delas associadas a questões bastante pontuais da atividade docente cotidiana como adequação da linguagem para uma dada faixa etária, como aponta a professora Leila, e conhecimentos

\footnotetext{
${ }^{12}$ Ao tratar da formação na universidade, afirma PérezGómez (1995) que as características de incerteza, singularidade, complexidade e conflito da sala de aula podem permitir aos futuros professores uma formação efetiva para o trabalho cotidiano na escola, ampliando seus conhecimentos e formas de ação para além daquelas difundidas no meio acadêmico; algo que, para os professores em início de carreira, parece, de fato, se efetivar.
} 
no campo da psicologia, sobre hiperatividade, por exemplo, que permitisse ajudar seus alunos, como afirma a professora Aline. Duas professoras destacam o valor daquilo que foi aprendido na universidade e que se pode "transpor" para a sala de aula:

"As atividades de geomorfologia, cartografia (maquetes, croquis, cartas) e toda vivência de trabalho de campo foram enriquecedoras e transferíveis para a sala de aula. Os resultados são maravilhosos...” (professora Clara);

"Lembro mesmo das aulas de prática de ensino de geografia e até aplico algumas coisas que aprendi”. (professora Mariana) (destaques nossos).

Mesmo ao expressar a necessidade e valorizar conhecimentos "aplicáveis" à sala de aula, os professores respondentes percebem também que a docência não se restringe à aplicação de técnicas. Como afirma o professor Pedro, a graduação contribuiu para sua atividade em sala de aula na medida em que permitiu que compreendesse que "a prática docente ultrapassa a noção de ensino-aprendizagem". Ensinou-lhe que a docência, associada às atividades rotineiras que 0 professor deve desenvolver em sala de aula, é uma atividade que exige do professor um entendimento do contexto social da escola em que atua. Já a professora Aline destaca que o curso a auxiliou a estar em permanente reflexão sobre sua prática. Segundo ela, o que mais foi importante na sua passagem pela universidade "foi perceber que estamos em CONSTANTE processo de formação" (destaque da professora).

Essas são algumas das discussões que emergem dos relatos de um conjunto de professores iniciantes de geografia. Tal como afirma Huberman (1992), mesmo havendo certas particularidades entre os diferentes sujeitos segundo sua trajetória, experiências de vida e contextos de atuação profissional, é possível apontar elementos que caracterizam as diferentes etapas daquilo que denomina o ciclo de vida dos professores. Acreditamos que os professores em início de carreira, pelas experiências que vivenciam, pelas suas necessidades objetivas e pela sensibilidade que possuem para certas questões em torno da atividade docente, em especial relacionadas ao aspecto da sua aprendizagem profissional, possam trazer em seus relatos importantes e ricas discussões para pensar esse complexo processo.

\section{Conclusões e considerações finais}

Como apontam a literatura acadêmica e os dados desta pesquisa, tornar-se professor não é um processo linear, plenamente planejado e com um traçado previsível. Tampouco ocorre de um momento para o outro, de maneira simples e fácil para aqueles que se tornam professores, por opção ou por contingência; aprender a ser professor é um processo longo e complexo. Somadas as características dos cursos de formação acadêmica para o magistério e as condições sobre as quais se realizam a inserção profissional dos jovens professores, o que resulta são processos de aprendizagem profissional ocorridos a duras penas, que demandam dos professores enormes esforços e geram, para muitos, grandes inquietações e reflexões.

A leitura e análise dos questionários respondidos por um conjunto de professores iniciantes de geografia da educação básica, associadas a alguns debates no campo da formação docente e da temática da iniciação à docência, possibilitaram capturar e tecer reflexões em torno de ricos elementos para a compreensão da aprendizagem da carreira por parte de jovens professores. Esse exercício nos permitiu elucidar uma série de questões em torno da trajetória de vida e da 
iniciação à docência e identificar possíveis relações e/ou influência sobre os processos de aprendizagem da profissão por parte dos professores nessa etapa da carreira, aqui, de maneira mais pontual, professores iniciantes de geografia.

Os debates propostos para desenvolvimento deste artigo, os caminhos percorridos até a "escolha" pela licenciatura em geografia como curso superior e as relações dessa etapa da formação com a atividade dos professores em seus primeiros meses/anos de magistério nos proporcionaram algumas pistas e chaves para o entendimento mais sistemático dos processos de aprendizagem da docência, tal como solicita o tema. Destacamos as fartas e ricas discussões em torno das concepções e ações acerca da formação de professores e seus desdobramentos para a aprendizagem profissional da docência dos professores iniciantes que responderam ao questionário.

No que se refere aos processos de formação acadêmica, os professores chamaram atenção para a necessidade de que os cursos cuja finalidade é formar professores, neste caso específico, de geografia, voltem-se para a escola e a tomem como referência principal para sua organização e desenvolvimento curricular. Valorizam os formadores que têm contato mais direto com a escola e os sujeitos que a fazem (e se fazem) nesse espaço e as disciplinas que os colocam, ainda enquanto futuros professores, em contato direto com esse que será seu ambiente de trabalho. Acreditam esses professores em início de carreira que, talvez dessa maneira, seja possível construir um processo de formação acadêmico para a docência menos ideal, ou mais condizente com a realidade, reduzindo os impactos, ou o "choque de realidade", quando da iniciação à docência.

Outro aspecto para o qual chamam atenção esses professores, ainda sobre os pro- cessos de formação acadêmica e a iniciação à docência, é a dicotomia entre as denominadas "teoria e prática”. Apesar de valorizarem fortemente as disciplinas mais "práticas", esses professores reconhecem a importância desse conjunto de disciplinas e não apontam para seu abandono. O que demandam é uma abordagem mais condizente com a prática da docência que virão a desenvolver, trazendo o já desgastado debate sobre "teoria e prática" para outro nível. Diferentemente de concepções dicotômicas sobre o tema, cuja resposta é quase sempre a supressão das disciplinas “teóricas" em detrimento das "práticas”, esses jovens professores trazem a discussão para outro nível: Que teoria(s) para formar (que tipo de) professores?

Como parte de suas experiências e vivências, acreditamos que especialmente vinculadas ao momento da carreira no qual se encontram, esses professores reconhecem que a formação do professor não é algo meramente técnico e não se esgota com sua diplomação. Apesar de fazerem avaliações críticas em torno da formação acadêmica, reconhecem que muitos aprendizados fundamentais sobre a escola e a atividade da docência, não restritos às técnicas de ensino, foram concretizados nesse momento da formação. No que se refere ao entendimento da formação como processo, é possível perceber, nos relatos desses professores, que a entrada na escola desencadeou uma série de aprendizagens e reflexões em torno da própria prática e uma avaliação problematizadora da formação na universidade.

Analisar as trajetórias e percursos das escolhas e dos processos de formação docente tomando como ponto de partida o relato de professores em início de carreira nos parece um caminho fértil para compreensão da aprendizagem profissional da docência por parte de professores iniciantes. Isso porque nos relatos desses professores (pelo momento 
profissional que vivenciam, as demandas dele provenientes e seus desdobramentos em termos de experiências e de reflexões) nos possam ser fornecidos elementos que permitam potencializar as possibilidades empírico-analíticas sobre a aprendizagem da docência.

Certos de que ainda há um longo caminho a percorrer, acreditamos que mesmo diante de uma multiplicidade de experiências, as trajetórias dos professores iniciantes que colaboraram com esta pesquisa respondendo ao questionário nos permitiram identificar elementos que são importantes para a construção de um entendimento mais amplo e complexo dos processos de aprendizagem profissional da docência por parte de jovens professores.

\section{Referências}

ABARCA, J. C. Profesores que se iniciam en la docencia: algunas reflexiones al respecto desde América Latina. Revista Iberoamericana de Educación, n.19, p.51-100, enero/abril 1999. Disponível em: <http://www.rieoei.org/oeivirt/rie19.htm>. Acesso em: 15 jan. 2012.

ANDRÉ, M. Pesquisas sobre formação de professores: tensões e perspectivas. FONTOURA, Helena Amaral da, SILVA, Marco (Orgs.). Formação de professores, culturas: desafios à pós-graduação em educação em suas múltiplas dimensões. Rio de Janeiro: ANPEd Nacional, 2011. Disponível em: <http://www.fe.ufrj.br/ anpedinha2011/livro2.html>. Acesso em: 14 set. 2011. (Coleção Anped Sudeste 2011, livro 2)

BRITO, A. G. et al.Inducción profesional docente. Estúdios Pedagógicos, v.31, n.1, p.51-62, 2005.
DINIZ, M. S. Professor de geografia pede passagem: alguns desafios no início da carreira. 263 p. Tese (Doutorado em Geografia) - Universidade de São Paulo, São Paulo, 1998.

DINIZ-PEREIRA, J. E. A formação acadêmico-profissional: compartilhando responsabilidades entre universidades e escolas. TRAVERSINI, Clarice et al. (Orgs.). Trajetórias e processos de ensinar e aprender: didática e formação de professores. 1. ed. Porto Alegre: EDIPUCRS, 2008, v. 1, p. 253-267.

FANFANI, E. T. Consideraciones sociologicas sobre profesionalización docente. Educação e Sociedade, v.28, n.99, p.335-353, maio/ago. 2007.

FREITAS, M. N. de C. Organização escolar e socialização profissional de professores iniciantes. Cadernos de Pesquisa, n.115, p.155-172, março/2002. Disponível em: < http://www.scielo.br/pdf/cp/n115/a06n115. pdf $>$. Acesso em: 20 maio 2010.

GARCIA, M. M. A.; ANADON, S. B. Reforma educacional, intensificação e autointensificação do trabalho docente. Educação e Sociedade, v.30, n.106, p.6385, jan./abril 2009.

GAUTHIER, C. et al. Por uma teoria da pedagogia: pesquisas contemporâneas sobre o saber docente. 2 ed. Ijuí: Editora Unijuí, 1998.

HUBERMAN, M. O ciclo de vida profissional dos professores. NÓVOA, António (Org.). Vidas de professores. Porto: Porto Editora, 1992, p. 31-61.

LIMA, E. F. de et al. Sobrevivendo ao início da carreira docente e permanecendo nela. Como? Por quê? O que dizem alguns estudos. Educação e Linguagem, ano 10, n.15, p.138-160, jan./jul. 2007. 
MARCELO GARCÍA, C. Pesquisa sobre formação de professores: o conhecimento sobre aprender a ensinar. Revista Brasileira de Educação, n. 09, p.51-75, set./out./nov./ dez.1998.

Formação de professores principiantes. In.:__ Formação de professores: para uma mudança efetiva. Porto: Porto Editora, 1999. pp.109-132.

A identidade docente: constantes e desafios. Formação Docente - Revista Brasileira de Pesquisa Sobre Formação de Professores, vol. 01, n.01, p.109-131, ago./ dez.2009.

MARIANO,A.L.S Apesquisa sobre professor iniciante e o processo de aprendizagem profissional: algumas características. 22005. Disponível em: http: <www.anped.org.br>. Acesso em: 19 maio 2010.

NONO, M. A. Casos de ensino e professoras iniciantes. 238 p. Tese (Doutorado em Educação) - Universidade Federal de São Carlos, São Carlos, 2005.

Professores iniciantes: o papel da escola em sua formação. Porto Alegre: Mediação, 2011, 176 p.

PÉREZ GÓMEZ, A. O pensamento prático do professor: a formação do professor como profissional reflexivo. NÓVOA, A.. (Org.). Os professores e sua formação. Lisboa: Dom Quixote, 1995, p. 95-114.

REALI, A M. de M; TANCREDI, R. M. S. P.; MIZUKAMI, M. da G. N. Programa de mentoria online para professores iniciantes: fases de um processo. Cadernos de Pesquisa, v.40, n.140, p.479-506, mai./ago. 2010.

REYES, L. A. O. Profesores principiantes e inserción profesional a la docencia: preocupaciones, problemas e desafios. Tese (Doutorado). Servilla: Facultad de Ciencias de la Educación, Univeridad de Sevilla, 2011, p.189-237.

SANMAMED, M. G. Formación docente: perspectivas desde el desarrollo del conocimiento y la sociolización profesional. Barcelona: PPU, 1995, 258 p.

TARDIF, M. Saberes docentes e formação profissional. Petrópolis: Vozes, 2002. 4 ed.

TARDIF, M.; RAYMOND, D. Saberes, tempo e aprendizagem do trabalho no magistério. Educação e Sociedade, Campinas, n. 73, p.209-244, dez. 2000.

Enviado em: 24/09/2012

Aceito em: 25/10/2012 